
spécialité

\title{
Salager-Meyer, Françoise and Beverly A. Lewin (eds.), Crossed Words: Criticism in Scholarly Writing
}

Bern : Peter Lang, 2011

\section{François Maniez}

\section{OpenEdition \\ Journals}

\section{Electronic version}

URL: http://journals.openedition.org/asp/2677

DOI: $10.4000 /$ asp. 2677

ISSN: 2108-6354

Publisher

Groupe d'étude et de recherche en anglais de spécialité

\section{Printed version}

Date of publication: 15 March 2012

Number of pages: $71-75$

ISSN: 1246-8185

\section{Electronic reference}

François Maniez, " Salager-Meyer, Françoise and Beverly A. Lewin (eds.), Crossed Words: Criticism in Scholarly Writing », ASp [Online], 61 | 2012, Online since 15 March 2012, connection on 04 November 2020. URL : http://journals.openedition.org/asp/2677 ; DOI : https://doi.org/10.4000/asp.2677

This text was automatically generated on 4 November 2020 .

Tous droits réservés 


\section{Salager-Meyer, Françoise and Beverly A. Lewin (eds.), Crossed Words: Criticism in Scholarly Writing}

Bern : Peter Lang, 2011

François Maniez

\section{REFERENCES}

Françoise Salager-Meyer and Beverly A. Lewin (eds.). 2011. Crossed Words: Criticism in Scholarly Writing. Bern: Peter Lang. 371 p. ISBN 978-2-0343-0049-0. 
1 Crossed Words: Criticism in Scholarly Writing, published by Peter Lang in the Linguistic Insights collection and co-edited by Françoise Salager-Meyer and Beverly A. Lewin, is a 371-page book made up of thirteen original contributions, each of which examines criticism in a particular genre or discipline or from a specific point of view. The book is divided into five sections: Method of Analysis, Genre Research, Intercultural/Cross-Linguistic Research, Cross-Disciplinary Research and Diachronic Research. It is our feeling as a reviewer that each of the contributions should be briefly summarized and evaluated, as they all contribute to the general architecture of the book.

2 Federico Navarro's study explores a sample of randomly selected Spanish

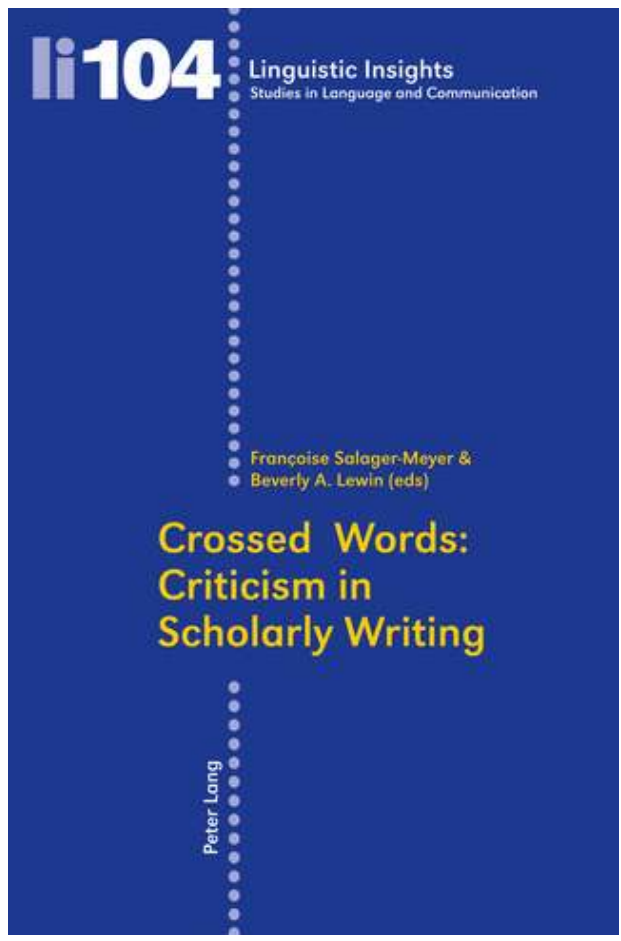
academic book reviews. Even though his corpus is relatively small (under 40,000 words) and specific (it is strictly composed of reviews of books published in Argentina in the 1940s and deals with linguistics and literary studies), the recursive method he uses for its exploration yields interesting results and allows him to outline a finegrained system of negative evaluative lexical and grammatical resources.

Esmat Babaii studies negative comments in a corpus consisting of ninety physics book reviews published in 1998 or 1999 in three leading physics journals (only 60\% of the original corpus is actually studied, as the remaining $40 \%$ concerns reviews that were purely descriptive or totally positive reviews). Here again, the corpus is small, but those with an interest in lexicology will appreciate his thorough description of the way words are used in negative evaluation, even though his classification of its various instances in five categories (affect, judgment, appreciation, engagement and graduation) is open to debate. Given the relatively recent publication date of the reviews under study, an interesting finding is the fact that the discipline of physics still allows the use of confrontational discourse that seems to be gradually disappearing from reviews in other disciplines.

Davide Simone Giannoni studies the deliberate use of impolite language in some editorials of the Journal of Clinical Investigation. Even though it is said that every issue in the journal's archive for the period 2000-2008 was scanned, only seven have been selected, presumably because of their highly contentious nature. As the contributor's corpus is very small, the results section is necessarily short, and while the subdivision used for out-group criticism (negative impoliteness, bald on-record impoliteness, positive impoliteness) is coherent, the fact that all instances of in-group criticism are actually instances of 'mock impoliteness' makes his classification less convincing. In some instances, the mention of a larger previous context would also have helped the reader better understand the classification choices that were made. 
5 Dimitra Koutsantoni studies a subgenre that has been so far relatively unexplored, reviews of rejected grant applications. The single-blind nature of the documents that make up her corpus (reviewers are anonymous, but they know the applicants' names) makes them stand out from the other corpora used in the book, as various factors such as the applicants' reputation, school of thought and occasional professional rivalries can affect the reviewers' evaluation. But even though reviewers' anonymous status affords them some degree of independence, the contributor shows how rhetorical strategies such as personal reference, hedging and complimenting come into play in the peer-reviewing process, since all reviewers will at some point find themselves in the position of having their own work evaluated by their peers.

6 Beverly A. Lewin and Hadara Perpignan study thirty-eight introductions to literary research articles (twenty of which are actually borrowed from a previous publication by another author) and show how the ways in which gaps and niches are established in such introductions vary substantially from what is often witnessed in social and hard sciences, as researchers tend to present their innovations without actually repudiating positions identified with a particular individual or school of thought. They also show that when innovations are presented as replacements for existing theory, they are often presented without articulating a defect in previous critical positions. The authors offer an interesting classification for the various types of innovation that they analyze in their corpus (replacement, extension, standing free, joining new wave, mediation, raising the alarm), although it is not clear whether the last two would necessarily achieve statistically significant presence in a larger corpus.

7 Seyyed-Abdolhamid Mirhosseini's contribution questions the peer review process for journal research articles. He describes the process of submission, review, resubmission and eventual rejection of an article that he himself wrote for an applied linguistics publication. He thus points out a number of inconsistencies among reviewers as well as in the different rounds of the review process. His call for a change in the system to make room for author-reviewer negotiation raises an interesting point and his arguments are generally convincing, but it is my opinion that his cause might have been better served if he had analyzed a similar sequence of events involving a colleague's scientific production rather than his own, as his objectivity in this instance might be called into question.

8 In the only cross-genre study in the book, Françoise Salager-Meyer and Ángeles Alcaraz Ariza show that accepted conventions may differ across genres within a particular discipline. Their introduction gives a very thorough summary of research in the field of academic criticism in the past twenty years and shows that a number of variation factors (across disciplines and cultures notably) have been studied. Their corpus is reasonably well-balanced among the six genres they chose to study in the field of medicine (editorials, review articles, research papers, case reports, book reviews and letters to the editor) and its size allows them to obtain statistically significant results that reveal a clear distinction between a highly critical group (book reviews and letters to the editor), a moderately critical group (editorials and review articles) and the least critical group (research papers and case reports).

Zofia Golebiowski examines scholarly criticism from two cultural perspectives: native language and discourse community. She compares two sociology papers written in English by native speakers (Text 1) and a native speaker of Polish (Text 2) to one written by a native speaker in Polish (Text 3), studying a particular type of relational 
structure, "concessional textual configurations which express authorial evaluative positioning through conceding and mitigating claims". Interestingly, she establishes her own niche by pointing to the lack of a clear definition of hedging, a notion that is generally taken for granted by the book's other contributors. Even though her corpus is very small (under 20,000 words), she successfully proves that the frequency of concessional structures gradually decreases from Text 1 to Text 3 , suggesting a certain degree of acculturation to the English-speaking academic community by non-native speakers.

In another cross-cultural study, Ana I. Moreno Fernández and Lorena Suárez compare critical comments in literature book reviews by writers from British/ American and Spanish cultures, showing that reviewers from these two cultures differ in the extent to which they affirm or suppress their personal identity in voicing criticism (among others, English-speaking scholars in their corpus tend to speak "on behalf of other readers" and never use the "exclusive we", or plural mayestático, that is frequently seen in Spanish). The exploitation of the average size corpus is scientifically sound and prompts the authors to formulate interesting hypotheses, notably that the difficulties faced by writers from non-Anglophone cultures in handling criticism might be related to differing notions of good face, a fact that is partly reflected in the extent to which writers intrude into their texts by means of so-called visibility and invisibility strategies.

11 Trine Dahl and Kjersti Fløttum examine the introduction section of research articles in linguistics and economics, in an attempt to establish whether the difference between linguistics (which they describe as more closely related to the humanities) and economics (supposedly more closely related to hard sciences) influences the way in which criticism and claim construction are expressed in those two disciplines. The study of three separate categories of criticism (of established knowledge/of methodological issues/aimed at promoting the writer's own work) yields interesting results that apply to both disciplines, showing that criticism is more personal and less hedged than previous studies seem to indicate. However, some of the oppositions studied in the various instances of criticism (personal vs. impersonal, hedged vs. unhedged) show no clear distinctions between the two disciplines involved.

Also focusing on introductions to research articles, Phuong Dzung Pho, Simon Musgrave and Julie Bradshaw observe how authors establish niches in applied linguistics and educational technology, showing that writers in the field of applied linguistics generally criticize existing research, while educational technology specialists tend to establish a niche by stressing the original character of their work. Using Lewin et al.'s (2001) framework for the analysis of the type of bearer and claim, they come up with some interesting results, notably a discrepancy between a very high number of claims of scarcity of data and a very low number of claims of obscurity of knowledge in educational technology. They suggest this may reflect the fact that the latter is a newly-established discipline, where there is more room for original work and challenges to previous research need not be voiced aggressively.

Bojana Petric studies book reviews published over a 100-year period in the oldest Serbian scholarly journal, producing a diachronic analysis that focuses on three particular decades (the 1900s, 1950s and 2000s). The comparison of ninety reviews (thirty in each time period) shows a sharp drop in the number of critical book reviews as well as in the frequency of criticism over time. She observes more hedging and 
mitigation in criticism in the third period under study (the 2000s), reflecting a tendency for reviewers to avoid personal criticism, a fact that she suggests might be due to the dwindling size of the academic community. Although their length has roughly doubled in the past century, some other characteristics of book reviews seem to have remained constant: criticism tends to cluster in the middle section and the most common targets of criticism are specific content points.

In another diachronic study, Olivia Fong-wa Ha describes the evolution of music criticism in record reviews from a British music journal, using as samples four ten-year intervals starting in 1921, 1946, 1966 and 1986. The results obtained from her relatively small corpus (under 20,000 words) clearly show that critics have tended to favor praise over criticism regardless of the time period under consideration (with unmitigated praise always outweighing unmitigated criticism), and suggest that record reviews have gradually become less informative and more evaluative over time. In all time periods, positive closing remarks outnumber negative ones, a fact which reflects Hyland's (2000) claim that reviewers prefer to use a closing complimentary remark to reassure community members of their reliability and reasonability.

In keeping with the latter statement, and reversing the given order of praise-criticism pairs (the so-called good news/bad news strategy), this reviewer will mention some areas where there was room for improvement: first comes the obvious lack of balance between the five main sections (Method of Analysis contains one article, while Genre Research accounts for about half of the total of the volume). Considering that many authors are quoted throughout the book, a unified bibliography would have made sense, and an index of proper names would also have been a welcome addition. Be that as it may, and in spite of the fact that some of the studies presented here are based on very small corpora and cannot make claims to generalization, they all contribute to a better understanding of what is at stake when scholars express their opinion on work produced by their peers, and a few of them actually shed light on some recent trends that had not been brought to light before. It is consequently clear to this reviewer that Crossed Words: Criticism in Scholarly Writing is worth reading for anybody with an interest in the long and tortuous process that constitutes the development of modern science.

\section{BIBLIOGRAPHY}

Hyland, Ken. 2000. Disciplinary Discourses: Social interactions in academic writing. London: Longman.

Lewin, Beverley A, Jonathan Fine and Lynne Young. 2001. Expository Discourse: A genre-based approach to social science research texts. London: Continuum International Publishing Group Ltd.

\section{AUTHORS}

\section{FRANÇOIS MANIEZ}

Université Lumière Lyon 2/CRTT EA4162 